\title{
A CAMBIANTE IMAGEN DE NAPOLEÓN EN ESPAÑA: DEL RETRATO IMPERIAL A LA BESTIA APOCALÍPTICA Y SU DESMEMORIA
}

JESUSA VEGA

Departamento de Historia y Teoría del Arte. Universidad Autónoma de Madrid jesusa.vega@uam.es

\begin{abstract}
Resumen: La guerra contra Napoleón significó la súbita y rápida transformación de su imagen entre los españoles quienes, con motivo de la alianza política, habían seguido su fulgurante carrera a través de los textos de los diarios y las estampas. Tras la batalla de Bailén y la retirada temporal de los franceses de Madrid comienza una nueva personificación caricaturesca de Bonaparte de notable influencia inglesa. Entre la imaginería que se creó exprofeso tuvo enorme impacto entre los españoles la alentada por Rudolf Ackerman, editor londinense que decidió dedicar una parte de su producción a la causa española. Veinte años más tarde, en 1834, la silueta de Napoleón se entendía como la de un personaje extraordinario entre los mismos españoles.
\end{abstract}

Palabras clave: Napoleón / Caricatura / Guerra de la Independencia / España / cultura visual.

\section{THE SHIFTING IMPRESSION OF NAPOLEON IN SPAIN: FROM THE IMPERIAL PORTRAIT TO THE APOCALYPTIC BEAST AND ITS FORGETFULNESS}

Abstract: If there is one historical figure whose representation turns suddenly upside down this is Napoleon among the Spaniards: from being the symbol of glory he became that of evil in the shortest time imaginable. The news of what was going on in Madrid soon arrived to the United Kingdom, but it was not until the battle of Bailén, that the English people turned their eyes to Spain. Maybe because of this previous relationship with Spain, Ackerman decided to turn part of his activity to the Spanish war and contributed to turn Napoleon's image from friendly to evil. But nothing lasts for ever, not even the bad image of Napoleon among the Spaniards; twenty years after the end of the war, in 1834, a new print with his image in silhouette Napoleon is named as an extraordinary man.

Key words: Napoleon / satirical print / Peninsular War / Spain / visual culture.

Si existe en la historia de España una figura cuyo retrato y representación súbitamente se transformaron de varón admirable a bestia apocalíptica digna de las mayores condenas, esa fue la de $\mathrm{Na-}$ poleón Bonaparte. No cabe la menor duda sobre las razones que provocaron este acelerado cambio, ni es nuestra intención ocuparnos de ese tema ni de la iconografía del personaje cuyo estu- dio, con motivo de las recientes conmemoraciones, ha renovado cuantitativa y cualitativamente la bibliografía. Nuestro objetivo es tomar en consideración la ausencia, es decir, la desaparición del personaje del archivo visual que hemos conservado en España a pesar del lugar preferente que ocupó en él. Ni siquiera el célebre retrato ecuestre del Primer Cónsul cruzando los Alpes, pintado por

* Fecha de recepción: 15 de abril de 2018 / Fecha de aceptación: 18 de junio de 2018.

* * Este artículo se inserta en el proyecto de investigación "La herencia de los sitios reales: Madrid, de corte a capital (H2015hum 3415) de la convocatoria de programas I+D de Ciencias Sociales y Humanidades (2015) de la Comunidad de Madrid, financiado por el Fondo Social Europeo. Agradezco a Isabel Tuda su constante apoyo y vaya también mi agradecimiento para Margarita Olmo Ruiz cuya generosidad, facilitándome la fotografía de la estampa La sombra de Napoleón que se encuentra en su colección, ha hecho posible que ilustrara mi trabajo. 
David a instancias del embajador español en Francia, que se salvó de la destrucción, se quedó por aquí; se lo llevó el rey José cuando definitivamente se retiró de España.

El interés de Napoleón en la prensa periódica francesa y su control a partir del decreto del 17 de enero de 1800, tuvieron un efecto inmediato en los periódicos españoles, encabezados por la Gaceta de Madrid cuyos constantes artículos "no eran por regla general sino meras traducciones de textos sacados de la propia prensa francesa que, asimismo, no solían dar lugar al más mínimo comentario". ${ }^{1}$ Contribuyó a consolidar esta imagen ascendente de aquel que "nació para triunfar de los hombres y avasallar la fortuna", según la crónica de la situación de sus ejércitos en Siria publicada en el Mercurio de España en octubre de 1799 (p. 2), la distribución de retratos de los cuales apenas han quedado vestigios, más allá del rastro fragmentario dejado en otros registros como son los valiosos inventarios que poco a poco se van dando a conocer. Sirva de ejemplo en el tema que nos ocupa el retrato de "Buena Parte" que adornaba una cajita tasada en 30 rs. de vellón y que fue parte de la dote que aportó María Josefa Surbille Abad Wautres y Cifuentes con motivo de su matrimonio con Tomás de Estada y Lancer, guardia de corps de la Compañía Flamenca en mayo de 1803.² Como recuerda González de las Heras, la presencia de retratos de los reyes y figuras relevantes entre las pinturas y pertenencias que componían el ajuar familiar era bastante frecuente en los núcleos urbanos en general, y en Madrid en particular, pero todavía era más común ponerlos en las múltiples cajas que se utilizaban tanto en el ámbito doméstico como en los complementos de vestir. La Real Fábrica de Cajas estaba ubicada en la calle Jacometrezo, en la calle del Olivo había otra fábrica de cajas, la mayor parte de los plateros hacían cajas, se importaban constantemente de Francia, Italia e Inglaterra, y había especialistas en pintar y adornar este tipo de objetos siendo común emplear estampas para este fin. Debió ser muy elevado el número de cajas que llevaron el retrato de Napoleón, a pesar de ello solo hemos recuperado hasta ahora un caso concreto, el anuncio intercalado en el Diario de Madrid del 23 de agosto de 1805. Según se lee, en la librería de Argueta de la calle de la Montera y en el puesto de Sánchez, situado en la calle de Carretas "frente a la casa de Filipinas", se podía adquirir la

estampa nueva que en un pequeño círculo están las armas y retratos del Emperador Buonaparte y su esposa: en las dichas armas están puestos en enigma los dichos retratos en el águila que está en medio de color de oro, y está arreglada para cajas o cuadros pequeños.

La estampa iluminada costaba dos reales, en negro la mitad, y por docenas se hacía una atención al comprador. Este testimonio da una idea de la difusión que tuvo el retrato de Napoleón, gracias a la importación de pinturas y estampas y, sobre todo, a la copia sistemática que hicieron los artistas locales, siempre atentos a las novedades procedente de fuera, principalmente de París, pues la fiabilidad de la información sobre los rasgos del retrato era clave; recordemos que en esos momentos se estaba afianzando la exactitud que ofrecía la técnica del fisionotrazo en el pronto registro del perfil. ${ }^{3}$ Pero, en la misma medida, la desaparición de todos estos materiales también da idea de la sistemática destrucción de la que fueron objeto. Una de las fuentes principales que tenemos para rastrear esa presencia, y sonora ausencia tras la invasión, es el Diario de Madrid donde, a partir de 1796, comenzaron a publicarse anuncios de estampas y composiciones laudatorias en honor al personaje. Madrid era un gran centro difusor. Desde la capital podían remitirse en carta, se distribuían a través de los vendedores ambulantes y, lógicamente, se utilizaba la red comercial que existía entre librerías, estamperías e imprentas.

Como es sabido, el Tratado de San Ildefonso (16 de agosto de 1796) supuso un vuelco en lo que se refiere a la política cortesana española con relación a la Revolución Francesa, sus efectos se apreciaron inmediatamente en el comercio incluido el de estampas. Entre los anuncios que se insertaron en el periódico madrileño el 16 de septiembre de ese mismo año de 1796 encontramos el siguiente:

En la librería de Escribano calle de las Carretas se venden estampas iluminadas que representan los trajes ordinarios y de ceremonia que usan los individuos del Directorio Ejecutivo de París su precio a 4 rs. cada una y pueden ir en carta.

La venta de la colección se continúo en esa librería, en las mismas condiciones y precios, y lo sabemos porque siguió anunciándose en el Diario de Madrid hasta completarla. El 3 de octubre se in-

\footnotetext{
1 LARRIBA, Elisabel. 2008, pp. 240-241.

2 GONZÁLEZ DE LAS HERAS, Natalia. 2014, pp. 294-295.

3 VEGA, Jesusa. 2010, 271-310.
} 
formaba de la "continuación de los trajes de las autoridades constituidas en Francia, dos estampas que representan el del consejo de los quinientos y el de los ancianos"; el 4 de noviembre se añadían "el traje del Secretario del directorio ejecutivo" y el "de los seis Ministros"; el 4 de enero de 1797 las estampas de los trajes del Mensajero de Estado y del Portero; y el 23 de febrero se daban dos trajes más, el que "usa el alto tribunal de Justicia" y el que se llevaba en el Tribunal de Casación. Con este último anuncio se daba por terminada la serie y a partir de entonces se podían adquirir las estampas juntas o separadas. Apenas unos meses antes, el 16 de octubre de 1796, se había puesto a la venta en la misma librería "el Retrato de Buonaparte, General del Ejército de la República Francesa en Italia. Grabado al Estilo inglés. Su precio 4 rs.", hasta el momento es el primer retrato que hemos encontrado anunciado de quien pondría fin precisamente al Directorio. El 29 de diciembre de 1796 se informaba que seguía a la venta en la librería de Escribano y también se podía adquirir "en el puesto del Diario junto a los Consejos"; el texto del anuncio era más escueto: "Retrato de Bonaparte, General del Ejército de la República francesa en Italia, se venden iluminados y sin iluminar".

La progresiva presencia de Napoleón en la Gaceta de Madrid -y recordemos que la lectura de este periódico era en voz alta-, y en el Mercurio de España a partir de $1797^{4}$ tendrá su correspondiente eco en el Diario de Madrid donde algunos lectores las seguirán con fruición, ${ }^{5}$ siendo relativamente frecuente encontrar composiciones laudatorias a su figura. Así, por el número del 25 de febrero de 1797 sabemos que "oyendo una señorita leer en la Gazeta de Madrid las grandes ventajas del general Buonaparte", cantó la siguiente seguidilla:

\author{
Mucho mayor que Aníbal \\ Te considero; \\ Pues de aquel nos lo cuenta, \\ Y en ti lo vemos. \\ Todos lo crean; \\ Porque mis seguidillas, \\ No son boleras. ${ }^{6}$
}

Cualquier excusa era buena para ensalzar a Napoleón, desde los versos dedicados a la amada, ${ }^{7}$ hasta el sesudo elogio escrito en latín: sus triunfos en Egipto eran los que se celebraban en el juguete inventado por "C. O." con motivo de la feliz inoculación llevada a cabo por el doctor Francisco Martínez Sobral en las personas del Príncipe de Asturias y sus hermanos. ${ }^{8}$

Fueron diversas las composiciones poéticas que se publicaron en las que es posible ver reflejada la ascendente carrera y los triunfos de Napoleón que se narraban en la Gaceta y el Mercurio. El 31 de mayo de 1797, en la primera página del Diario de Madrid, se comunicaba a los lectores que "habiendo leído el autor en la Gaceta de Madrid las gracias, honras y distinciones que mereció al General Buonaparte el pequeño lugar del nacimien-

\footnotetext{
${ }^{4}$ Entre otras noticias se insertó la siguiente: "El ciudadano Legros de edad de veinte y cinco años, discípulo del célebre David, acaba de concluir en grande el retrato de Buonaparte en Arcolo, empuñando una bandera y gritando con la espada en la mano: Soldados, seguid a vuestro General. Todos los artistas admiran esta composición"; en "Noticias de Roma", Mercurio de España, mayo de 1797, p. 9.

${ }^{5}$ Al menos eso se desprende del irónico desencanto que sufrió el autor de la carta, remitida el 27 de noviembre de 1799, al comprobar que la descripción del Valle de Carranza no hacía referencia a una nueva empresa del "valeroso Buonaparte", quien ponía cualquier lugar de actualidad "por su magnanimidad y pericia"; no obstante, la redacción es tan ambigua que no es posible saber si con el escrito está ironizando el protagonismo alcanzado por Napoleón entre los españoles.

${ }^{6}$ Además de en las coplas, la figura de Napoleón pasó también a ser protagonista de todo tipo de composiciones musicales, sobre todo a partir de la coronación: por ejemplo, por el Diario de Madrid del 11 de enero de 1805 sabemos que en la librería de Dávila se vendían juntos el "minué afandangado y el de Buonaparte" y allí seguían a la venta por el precio de 4 rs. el 26 de junio. Por otro lado, no sabemos si es el mismo "minué" que estaba de venta en la librería de Campo, de la madrileña calle de Alcalá, y se anunciaba en el Diario de Madrid del 6 y 29 de noviembre de 1806; tampoco sabemos si es el mismo "minué" que se vendía en la librería de Esparza, ubicada en la Puerta del Sol, pero es probable que todos fueran diferentes, entre otras razones porque estos últimos se vendían a 6 rs. (Diario de Madrid, 24 de agosto de 1807). Y no todo fueron "minué", también se pusieron a la venta el 21 de diciembre de 1805, en el almacén de papel rayado que estaba ubicado en la Carrera de San Jerónimo, "seis vals para piano alusivos a la coronación de Buonaparte, a 10 rs. el juego", y seguían en venta el 9 de diciembre de ese año.

7 En el Diario de Madrid de 7 de marzo de 1798 se publicó la oda titulada "A mi Rival", unos versos compuestos a la espera de que alguien los pusiera música donde se introducen dos personajes relevantes del momento en la ciencia y la guerra: Newton y Napoleón.

${ }^{8}$ El juguete que fue libremente traducido y publicado unas semanas más tarde por "Lidoro de Seréne", en la traducción la exaltación pasó de ocupar los seis versos iniciales a diez; vieron la luz en el Diario de Madrid del 28 de noviembre y del 31 de diciembre de 1798 respectivamente. AGUILAR PIÑAL, Francisco, 1981, p. 325, registra 23 asientos bajo este nombre y los de "Lidoro Sirenaye" y "Lidoro" a secas.
} 
to de Virgilio" le había compuesto un madrigal; y por haber respetado la patria del poeta latino el 10 de junio de ese mismo año, también en primera página del Diario de Madrid, se daba un largo elogio que terminaba así:

\section{De Buonaparte y de Marón los nombres, Suena otra vez, y oyendo al heroísmo Gritar, no hay más allá, cesó mi imperio Dijo, mi centro rompa, \\ Y sonando otra vez rompió su trompa.}

Más allá de la calidad, lo que parece que no tiene duda es que estas composiciones eran bien recibidas por el público y ni siquiera era necesario ya poner el nombre completo para que fuera reconocido Bonaparte. ${ }^{9}$ El mismo José Mor de Fuentes, cuando recuerda que en 1800 publicó el tercer tomo de sus poesías en su "Bosquejillo de la vida y escritos", nombra expresamente la "Oda dedicada a Buonaparte", y lo hace casi en los mismos términos en los que fue anunciado en el Diario de Madrid del 22 de diciembre de ese año:

Contiene una zarzuela intitulada: la Presumida, y varias composiciones sueltas; entre ellas una oda a la física, otra a Don Francisco Goya sobre la pintura y la poesía, y otra al regreso de Buonaparte a Europa, la cual se ha publicado con la traducción francesa en la década filosófica de París. Se hallarán a 4 rs. en la librería de Castillo, frente a las gradas de San Felipe el Real.

Si a través del texto el personaje de Napoleón se hizo familiar a los españoles, fue gracias a las estampas, esculturas y pinturas como su efigie y figura llegaron posiblemente a todos los rincones de la Península. En cuanto a las estampas, tras la que se puso a la venta el 29 de diciembre de 1796 no hemos localizado ningún anuncio en el Diario de Madrid hasta el 14 de julio de 1797 y dice así:

Estampa nueva del retrato del general Buonaparte a caballo el cual está dando disposiciones a una columna de Infantería y Úsares que va marchando al frente de su campamento llevando delante su artillería. Véndese en la Librería de Hurtado, calle de las Carretas en los puestos del Diario plazuela de Santo Domingo y frente a Santo Tomás su precio $5 \mathrm{rs}$.

Seguían vendiéndose a final de año, según se anunció en la Gaceta de Madrid del día 5 de diciembre, pero se había rebajado el precio a 3 rs., hecho que puede indicar que no tuvo mucha demanda, pero también pudo ser que se buscara un precio más competitivo debido a la competencia pues un retrato similar se puso a la venta en la li- brería de Escribano desde el 21 de agosto de 1797 en que se anunció en el Diario de Madrid. De este último no sabemos el precio, aunque sí que se trababa de "estampas apaisadas de medio pliego de marca mayor". Por esta noticia debemos pensar que una imagen parecida, sino la misma, se empleó para abanicos según la información de los que se pusieron a la venta en la fábrica establecida en el número 45 de la calle angosta de Peligros. A esta abaniquería llegaron, según se decía en el periódico el 28 de julio de 1797, "un surtido de ellos de todas clases hechos en dicha fábrica y entre ellos los hay con Buonaparte a caballo, en seda y bordados, los que se darán con equidad".

Como vemos, la presencia del general francés iba más allá de librerías, puestos y estamperías, llegaba a las tiendas de novedades donde se ofrecían todo tipo de complementos de moda. Un ejemplo es el anuncio insertado el 21 de agosto de 1797 por los responsables de la tienda número 5 de la calle Jacometrezo, entrando por la Red de San Luis:

Acaban de llegar de Francia una partida de pañuelos Bearneses a los precios siguientes: Pañuelos de vara fondo oscuro de cuadros y sin ellos a 12 y 14 rs.; dichos de 3 cuartas y media blancos y de fondo a $14 \mathrm{y}$ 16; dichos de id. de vara de cuadros a 18 y 20 rs.; dichos id. finos de ídem a 22 y 26; dichos id. de id. blanco y de colores de hilo y de yerbas a 24 . Abanicos de madera a 3, 3 1 1/2 y 4 rs.; dichos de Júpiter y otras figuras a 4, 5, y 6; dichos de historias, Buonaparte y otras figuras a 7, 8, y 10; dichos más finos de hueso y madera a 12 y 13 rs.; dichos de id. finos país de seda de lámina y mariposa 26; dichos de id. a 30, 40, y 50; y otros a 50 y 60; medias blancas de seda para hombre rolladas a 34, 36 y 40 con otros géneros.

En cuanto a pintura y escultura hay dos noticias que pueden ayudar a valorar la presencia del retrato de Napoleón en España. El 2 de junio de 1801 se informaba en el Diario de Madrid que se iba a proceder a la venta del cargamento apresado al "Mercurio" y, en el cargo confiscado -muebles, pianos, órganos, sombreros, libros, pastillas de olor y de jabón, perfumes, cajas, espejos de diversos tamaños y finalidades...-, se encontraba "una caja con varios cuadros y retratos de Buonaparte". Respecto a las efigies escultóricas, la noticia más relevante localizada es la iniciativa de Cayetano o Gaetano Merchi, escultor de origen italiano afincado en España. El 2 de noviembre de 1797, bajo el epígrafe "Escultura", el citado artista insertaba en el periódico el siguiente comunicado:

\footnotetext{
9 La primera página del Diario de Madrid, del 20 de noviembre de 1799, publicaba la composición de "S" dedicada "Al General B."
} 
Suscripción a la Estatua de Buonaparte, General en jefe de el Ejército de Italia.= D. Cayetano Merchi, Escultor italiano, conocido en París por haber trabajado allí durante 25 años y hecho las estatuas o bustos de los personajes más distinguidos de esta Corte ha dado ya pruebas de su talento en esta Corte, desde un año que hace que está en ella; y cediendo a las instancias repetidas de muchos aficionados deseosos de transmitir a la posteridad la estatua del general Buonaparte en jefe del Ejército de Italia, tiene el honor de proponer la suscripción siguiente: La estatua será de mitad naturaleza, es decir, de dos pies y diez pulgadas, medida española, que forman cabalmente la mitad de la estatura del héroe, sacado sobre una grabura [sic] recién venida de París, y que es la mejor de las que hasta ahora han parecido. Estará en su traje ordinario y en acción de mandar. Se admitirán Suscriptores hasta el n. de 30 . El precio será de una onza de oro por cada estatua en yeso. Los que la quisieren en barro cocido darán cuatro onzas, y en mármol de Italia 18.000 rs. La mitad del precio se pagará adelantado, y la otra mitad a la entrega de la obra. Dicho Merchi, deseoso de establecer su fama en esta Corte, como la estableció en París, se lisonjea con la esperanza de que los Sres. Suscriptores quedarán satisfechos por el esmero que pondrá en cumplir con su empeño. Se suscribirá todos los días en casa del autor, calle del Niño n. 9 esquina a la de Franco, cuarto bajo, en donde se verá el retrato del héroe, y las mudanzas que el artista ha tenido por conveniente hacer en él para el arte de la Escultura; también se verán los bustos de algunos personajes distinguidos de esta Corte. ${ }^{10}$ Se previene a los aficionados que también se ejecutará la estatua de estatura natural si se pide.

Como podemos ver poco a poco Napoleón se incorporó a la cotidianeidad de los españoles, hasta el catre de campaña que utilizaba se copió y se puso a la venta. ${ }^{11}$ Su retrato pasó a integrarse en los objetos más comunes, como son los cuadernos que se empleaban para las notas personales. Según se leía en la primera página del Diario de Madrid del 21 de enero de 1801, en las librerías de Millana, Barco y Quiroga, sitas en las calles de Preciados, San Jerónimo y Carretas respectivamente, se podía adquirir el libro de memorias, y otras curiosidades para este año de 1801, aumentado con el retrato de Buonaparte, en traje de Cónsul, sacado por el original venido de París, iluminado, el que también se venderá suelto a 2 rs. Este librito tan bien recibido del público, sirve para apuntaciones diarias, con sus hojas de cartulina, para sentar y poderse borrar alguna ocurrencia; lleva su lapicero adornado de estampitas finas, grabadas en París; los hay encuadernados en tafilete, pastas finas bordadas con sus estuches, y para mayor comodidad los hay ahora en carteras a la inglesa para llevar papeles y a la rustica holandesa, siendo el precio de estos últimos $6 \mathrm{rs}$.

La carrera de Napoleón contribuyó a renovar la oferta de esos años, el retrato "vestido de primer Cónsul" del tamaño de medio pliego, y "copiado del último que ha llegado de París, y por consecuencia debe ser el más parecido", se vendía en la librería de Castillo al precio de 6 rs. en negro y 10 iluminado (Diario de Madrid, 24 de enero de 1801). Para entonces desde las páginas de la Gaceta de Madrid se había alimentado "el retrato de un gobernante ideal y carismático que había conseguido regenerar su país y guiarlo por la senda de la felicidad". ${ }^{12}$ Nuevamente se volvió a renovar la oferta con motivo de su coronación como emperador. De este momento conservamos el que grabó Juan Brunetti en 1806, por dibujo de Joaquín Chailly, donde expresamente se dice que fue hecho en SaintCloud, es decir, en la residencia del emperador donde tuvo lugar la ceremonia (fig. 1). ${ }^{13}$ Esta última también se hizo presente a través de abanicos:

En la calle del Carmen, tienda inmediata al mesón de Segovianos, ha llegado un surtido de abanicos de papel y maderas finas, alusivos a la coronación de Buonaparte en la catedral de París con su explicación en el reverso, sus precios desde 8 a 12 rs. (Diario de Madrid, 1 de junio de 1805).

En esta ocasión sabemos que la demanda fue alta pues un mes más tarde, el 3 de julio, se avisaba por el periódico que a la misma tienda había "Ilegado nuevo surtido de abanicos de la coronación de Buonaparte de la misma clase y precio que los anteriores".

\footnotetext{
10 Entre otros, Merchi hizo el retrato en busto de Carlos IV que fue dibujado por Antonio Martínez y grabado por Juan Brunetti en 1799, año en que el artista fue nombrado Escultor de Cámara. Se conservan ejemplares en diversas colecciones, entre ellas en el Museo de Historia de Madrid (IN- 4583 y 15520). Entre los bustos de personajes famosos se cuenta el de Federico Gravina y Nápoli (Museo Naval, Madrid) y Francisco de Goya (Real Academia de Bellas Artes de San Fernando y Museo del Prado, Madrid). Para más información sobre el escultor véase AZCUE, Leticia 1991, vol. 3, pp. 1414-1418.

${ }^{11}$ El 4 de julio de 1806 se insertó este anuncio en el Diario de Madrid: "En la calle de San Marcos, n. 6, se venden con equidad camas y catres de fierro, perfectamente acabados, un catre copiado del que tiene Buonaparte en campaña, que le arman en dos minutos los más rústicos criados, y una escopeta de Madrid embutida en oro".

12 LARRIBA, Elisabel. 2008, pp. 244-245.

13 Se conserva ejemplar en el Museo de Historia de Madrid (IN, 2267).
} 


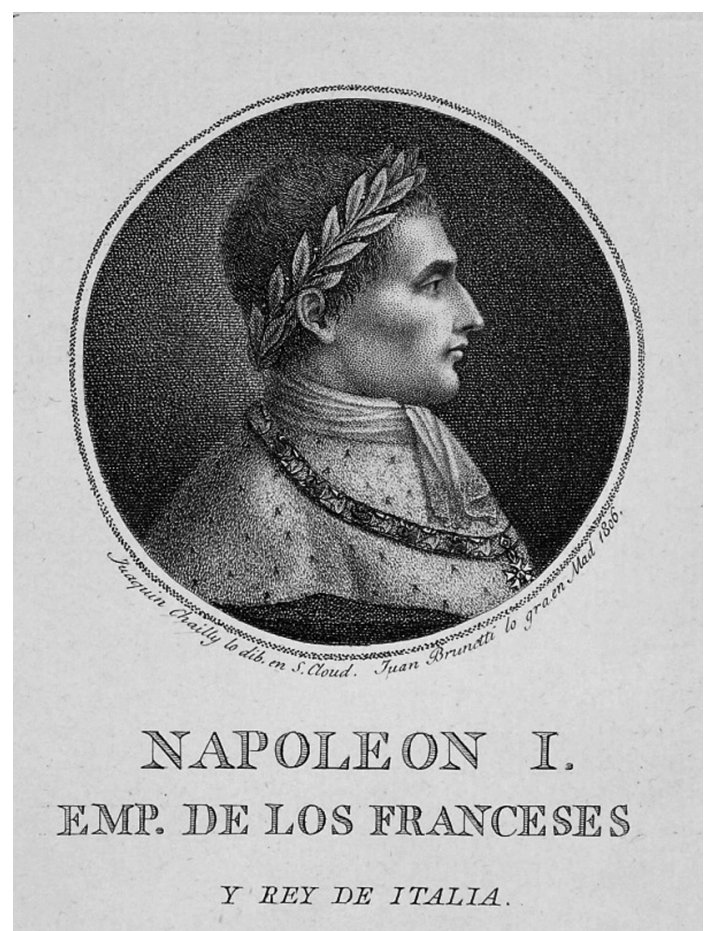

Fig. 1. Retrato de Napoleón emperador de los franceses y rey de Italia, grabado por Juan Brunetti, por dibujo de Chailly, 1806. Museo de Historia de Madrid.

En definitiva, Napoleón y su familia se incorporaron al repertorio iconográfico de los personajes de fama en todos los formatos y formas posibles, incluída la lúdica y atractiva moda de los retratos invisibles:

Estampa nueva que en los matices o colores de una mariposa grande y de un color hermoso están colocados en dos clases invisibles y patentes los retratos del Emperador Bonaparte y su esposa: en las de arriba los primeros están en los recortes de ellas, y los otros que son dos bustos en medio, guardando todos contraposición y simetría. Esta idea es de mucho gusto y más extraña y curiosa que el pájaro que tenía los retratos de la Real Familia, ${ }^{14}$ inventada por el mismo autor. Se hallará perfectamente iluminada de dos clases, color celeste y carmesí, en las librerías de Escribano y Gutiérrez, calle de Carretas, y de Manguera, calle del Carmen: su precio 4 rs.

A la vista de lo expuesto se constata que el personalismo que acompañó a la figura en la documen- tación textual se reforzó con la imaginería visual, pues como vamos comprobando en su mayoría se trata de retratos que sirven para enaltecer al militar, siendo rarísimas las estampas anunciadas con otras temáticas como, por ejemplo, el campo de batalla. Esta ausencia resulta rara pues hay que tener en cuenta que había una producción especializada en hazañas militares, en los años previos como consecuencia de la reciente guerra del Rosellón, en los posteriores como resultado de la guerra contra los franceses. Hasta el momento solo hemos localizado el anuncio que se insertó en el Diario de Madrid el 24 de enero de 1807:

Estampa que representa la gran batalla de Gena, ganada a los Prusianos por el gran Napoleón; Emperador de los franceses y rey de Italia, el 15 de octubre de 1806; e igualmente la entrada en Berlín por el Emperador. Se hallarán en la librería de Escribano y puesto de Gutiérrez, calle de las Carretas, plazuela de Santo Domingo, y en casa de Orea frente a San Luis; su precio a 2 rs. en negro y a 4 iluminada.

Ese mismo año de 1807 comenzó a publicarse la obra en diez volúmenes de La vida de Napoleón Bonaparte, emperador de los franceses, compilada por Pablo Antonio Arribas y dedicada, desde el tercer hasta el noveno volumen, a Manuel Godoy. En el anuncio de este último -publicado en el Diario de Madrid del 18 de diciembre de 1807- se daba el siguiente aviso:

A los libreros que quieran comprar la obra en papel se les rebajaran 4 rs. en los 9 tomos; y a los que paguen 15 ejemplares en papel, se les dará uno gratis en la imprenta de Albán, donde están sin encuadernar.

Nada se informa sobre el retrato del emperador que se encuentra encuadernado en algunos de los ejemplares que se conservan y, probablemente, la razón sea que este retrato fue resultado de otra iniciativa, o al menos eso cabe deducir de la información que tenemos: mientras que los libros se podían comprar en las librerías de Gómez Fuentenebro y Elías Ranz a 12 rs. en rústica, el retrato, grabado por Luis Fernández Noseret, se adquiría en la librería de Castillo. El anuncio se insertó en el Diario de Madrid del 23 de marzo de 1807, y decía que se vendía

suelto el retrato del mismo Emperador Napoleón en su traje regular, copiado de un original que acaba de llegar de Francia, dibujado y grabado por profesores de acreditada habilidad, el cual por su tamaño pue-

14 Se conserva ejemplar en el Museo de Historia de Madrid (IN, 13781), y representa los "retratos enigmáticos del Emperador Bonaparte, su Esposa, el Príncipe José Bonaparte Grande Elector y el Príncipe Luis Bonaparte Condestable, hermano del Emperador". 
de servir para adornar la vida de este héroe, que se está publicando traducida. ${ }^{15}$

En esos meses anteriores al levantamiento de los madrileños siguieron publicándose nuevos retratos. Por ejemplo, el 15 de enero de 1808 se ofrecía a través de las páginas de la Gaceta de Madrid la estampa que mostraba a "Bonaparte bajo el emblema de Hércules, significado en los 12 trabajos de éste"; además de venderse en diferentes librerías de Madrid, podía ir en carta. No hemos encontrado ejemplar, pero es muy posible que estuviera inspirado en el poema compuesto por T. J. Béguyer, presbítero francés y profesor de lenguas y matemáticas, que se anunció tanto en la Gaceta de Madrid como en el Diario de Madrid el 14 de febrero de 1806. Según se explicaba en este último periódico se trataba de un

Poema heroico al honor de Napoleón el grande, Emperador de los Franceses, y Rey de Italia en versos alejandrinos franceses. Este poema, que se compone de solo 150 versos, parecerá tal vez corto vistas las muchas acciones del héroe extraordinario que elogia; pero el lector no debe perder de vista que este género de poesía no admite detalles ni pormenores: ella debe solo presentar a su héroe adornado de sus principales atributos, como a Hércules en medio de sus trabajos, y al sol en lo más encumbrado de su carrera.

Poco después, el 7 de marzo, a través de las páginas del Diario de Avisos, se ponía a la venta en las librerías de Escribano y de Campo, al precio de 8 rs., la "estampa nueva en medio pliego de marca del retrato de Napoleón I vestido de capitán" dedicada al Embajador de Francia en la corte española, Francisco Beaucharnais. Se le veía de medio cuerpo y había sido dibujado "por el célebre retratista de Paris Mr. Isabey y grabado a puntos por Miguel Gamborino".

Una última observación cabe hacer al repaso de estos anuncios y se refiere al papel activo que tuvo la librería de Escribano en la fama de Napoleón y la actividad desarrollada por Juan Brunetti. Como hemos podido comprobar, en dicha librería se despachaban varias de las estampas que se anuncia- ban y, por su parte, el grabador dio un tratamiento al retrato del emperador similar al que eligió para la familia real española. Pero, además, en ese establecimiento se puso a la venta el grabado que hizo Brunetti del "Retrato del Almirante Nelson. Muerto por los Españoles en el combate del día 21 de Octubre de 1805, batiéndose contra el navío Sma. Trinidad", hecho por pintura de "D. Orme Ingles" (fig. 2). ${ }^{16}$ Es decir, el entreguismo a Napoleón no fue solo de las autoridades españolas, en las iniciativas de libreros y grabadores es clara la ausencia de toda hostilidad hacia Napoleón y los franceses, y refleja una figura que es plenamente acorde con la visión idealizada del gobernante carismático. Pocos días antes del levantamiento popular, el 26 de abril de 1808 -un mes más tarde de la entrada triunfal de Fernando VII en la capital tras la asunción de la corona española-, en las páginas de la Gaceta de Madrid se daba una descripción pormenorizada del cuadro donde JacquesLouis David plasmó la gran ceremonia de su autocoronación, noticia que ponía el broche de oro a la pormenorizada información dada por el periódico, ${ }^{17}$ la estampa probablemente no llegó y la fortuna de todos estos materiales cambió

La confrontación franco-británica hizo que los caricaturistas ingleses dejaran cumplida constancia de la sumisión y entrega de los españoles en sus sátiras contra el francés. El ejemplo más ilustrativo se encuentra en la espectacular estampa inventada y grabada por James Gillray, publicada por $\mathrm{H}$. Humphrey el 2 de diciembre de 1804 con el título The grand coronation procession of Napoleone the 1st, Emperor of France, from the Church of NotreDame. En ella vemos al solícito "don Diego", con traje antiguo, enorme y desfasadas botas, y de amarillo, quien se apresta el primero -tras él van Prusia y Holanda- para llevar servicialmente el manto imperial. ${ }^{18}$ No parece que fueran materiales que circularan por la Península, al menos no hemos encontrado rastro alguno de ello a pesar de que los sucesos de mayo de 1808 provocaron un auténtico vuelco en el mercado de estampas español.

\footnotetext{
${ }^{15}$ Se anunció junto al "Catecismo para uso de todas las Iglesias del Imperio francés, aprobado, propuesto y recomendado a todos los Obispos por el Emmo. Cardenal Caprara, Legado de la Santa Sede; adoptado exclusivamente y mandado publicar por el Emperador Napoleón, con un decreto del Cardenal Arzobispo de París, por el cual ordena aquel sabio Prelado que este Catecismo sea el único que se enseñe en su diócesis. Se vende traducido al castellano en un tomo en $8^{\circ}$ prolongado, adornado con una estampa, en la librería de Castillo, a 14 rs. en pasta y 12 a la rústica".

16 Se conserva ejemplar en la BNE (IBR/2173).

17 LARRIBA, Elisabel. 2008, pp. 56 y ss. En este contexto resulta, sin duda, realmente excepcional el "Muera Napoleón el invasor" grabado en los muros de la catedral de Pamplona, si de verdad fuera de 1804 pues no necesariamente son dos inscripciones relacionadas; por entonces, como hemos visto el nombre más común era "Buonaparte". Sobre estas inscripciones véase ORCÁRIZ GIL, Pablo. 2007-08, p. 296 y QUINTANILLA MARTINEZ, Emilio. 2012.

18 Se conservan ejemplares en negro e iluminada en el British Museum (Londres): 1863,0110.141 (BM Satires 10362.A); $1851,0901.1159$ y $1868,0808.7312$ (BM Satires 10362).
} 


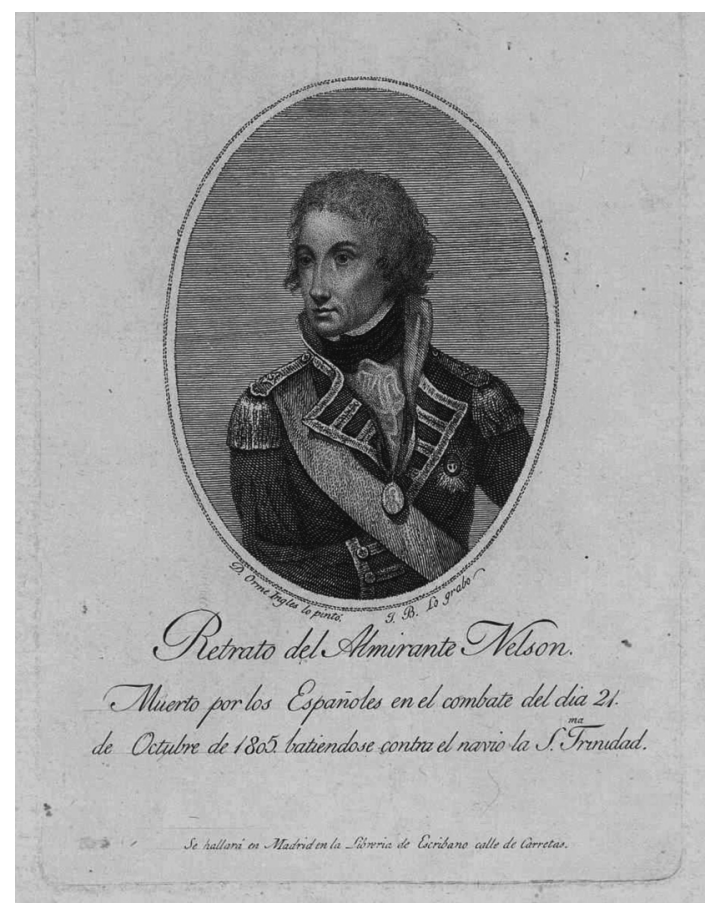

Fig. 2. Retrato del almirante Nelson, grabado por Juan Brunetti, por pintura de Orme, 1805. Biblioteca Nacional de España, Madrid.

El levantamiento de los españoles contra los franceses introdujo, como es sabido, sustanciales novedades en la imaginería de la caricatura inglesa en relación con la imagen de los españoles, sobre todo a partir de la Batalla de Bailén librada el 19 de julio de 1808. Esta transformación ha sido motivo de diferentes y renovados estudios sobre todo a raíz de las conmemoraciones recientes, razón por la que no vamos a ocuparnos sobre la nueva iconografía de Napoleón que circuló por la Península. Nuestro interés se centra en la figura del editor Rudolph Ackerman porque todo parece indicar que fue el más activo en tratar de llegar al público español, como señalaron en su momento Clayton y O'Connell. ${ }^{19} \mathrm{Gracias}$ a las nuevas investigaciones se puede entender mejor cómo tuvo lugar la difusión de la nueva imaginería entre los españoles.

No contamos todavía con documentación que explique ese particular interés de este emprendedor
Ackerman por los sucesos españoles, pero es muy posible que viniera de atrás. Del mismo modo que se ha apuntado que se estableció una relación comercial entre Gabriel de Sancha y el editor Boydell cuando el primero estuvo en Londres, y esto explicaría la existencia de estampas de este último en la librería madrileña, ${ }^{20}$ sabemos que Ackerman había entrado en contacto con relevantes personalidades españolas, como Agustín de Betancourt y su asistente, Bartolomé Sureda; ${ }^{21}$ de ahí quizá su interés por el mercado de estampas español. Sea como fuere, entre las estampas raras conservadas, se encuentra el ejemplar de la caricatura The Corsican Tiger at Bay!! de la Bodleian Library (Oxford) (fig. 3). La composición es obra de Thomas Rowlandson y fue publicada por Ackermann en Londres el 8 de julio de 1808. En los márgenes de esta prueba, en letras de imprenta, se han añadido en español los diálogos y nombres de los personajes. Se trata, por tanto, de un valioso testimonio que ilustra cómo se hizo comprensible toda esta compleja imaginería inglesa a los españoles y explican en parte su éxito. En el caso que nos ocupa, después de que circulara esta versión inglesa se puso a la venta la española donde se copió exactamente la composición, pero se introdujeron variaciones en los textos, es decir, se eliminó aquello que no se consideró conveniente.

Por otro lado, por las fechas se comprueba que Ackerman se interesó por la cuestión española incluso antes del triunfo de Bailén, es decir, casi desde un principio su compromiso con la causa fue decidido, y esto lo corrobora el texto de otra de las estampas raras que conservamos, Buonaparte, The Monstrous Beast (fig. 4), obra de James Girtin, en la que se lee: "Sold by R Ackermann, 101, Strand, where a variety of subjects on the present Spanish patriotic cause are published". ${ }^{22}$ Aunque no se indica la fecha podemos aventurarla, pues esta iconografía de Napoleón como bestia apocalíptica fue empleada a su vez por G. Sauley en la caricatura titulada The Beast as described in the Revelations, Chap. 13. Resembling Napolean Buonaparte, ${ }^{23}$ grabada por Thomas Rowlandson, y publicada también por Ackerman el 22 de julio de 1808. Lo mas probable es que Buonaparte, The Monstrous Beast viera la luz por esas fechas. Que Girtin y Sauley compartan la iconografía no es raro pues hay que

\footnotetext{
19 CLAYTON, Tim y O'CONNELL, Sheila. 2015, pp. 33-34. Sobre Ackerman, veáse HARRIS, Katherine. 2015.

20 SÁNCHEZ ESPINOSA, Gabriel, 2014.

21 VEGA, Jesusa. 2000, pp. 177-178.

22 Se conserva un ejemplar en el Musée National du Château de Malmaison (Rueil-Malmaison, Francia).

${ }^{23}$ Se conserva ejemplar en el British Museum (Londres), 1868,0808.7657 (BM Satires 11004).
} 
tener en cuenta que tampoco esta era muy original: la figura de la bestia apocalíptica se fundamenta en iconografías anteriores como la que figura en Sawney's defence against the beast, whore, Pope and Devil, estampa anónima publicada en 1779 a resultas del "Acta de Ayuda Católica". ${ }^{24}$

Sabemos que la circulación de estas estampas por la Península fue rápida y todo parece indicar que su incidencia en la nueva imagen de Napoleón que se lee en los textos también fue bastante inmediata. Por ejemplo la bestia, aunque no tiene fecha, se piensa que el folleto La Bestia de siete cabezas y diez cuernos, Napoleón emperador de los franceses: exposición literal del capitulo XIII del apocalipsis por un presbitero andaluz, que tuvo diversas impresiones en diferentes ciudades, es de 1808, y bien pudo tener como referencia las estampas publicadas por Ackerman; también parece que hace referencia a la estampa de Ackerman el franciscano valenciano Miguel Magraner y Soler, autor de La óptica del ciego de la embrolla y del mundi-novi en España, en el pasaje que describe la retirada de los franceses en julio de 1808:

la prisa, la confusión, el miedo, el asombro, la consternación y el atolondramiento en la huida del Rey Pepe, del dragón de las siete cabezas, arrastrado con su cola toda la canalla y maldita gente de renegados, de réprobos que le siguen. ${ }^{25}$

Imágenes, escritos y hechos dejaron claro a los españoles desde un principio que Napoleón era enemigo de España y a partir de ese momento tuvo lugar la destrucción sistemática del archivo visual construido como hemos visto en los años previos. A lo largo de los seis años de lucha y sufrimiento es difícil que hubiera alguien que no viera en él al enemigo a abatir salvo, claro está, los afrancesados entre los cuales se encontraba Leandro Fernández de Moratín a quien debemos, según opinión de Ángel Barcia, un torpe retrato dibujado de cuerpo entero sentado. ${ }^{26}$ Quizá porque sabemos cuan sangrienta fue la contienda y las tremendas secuelas que tuvo, nos sorprende aún más que esa imagen de bestia apocalíptica, hijo de Lucifer y monstruo del Averno se desvaneciera casi con la misma celeridad con la que se creó, pues veinte años más tarde, en el Diario de Avisos de Madrid del 18 de julio de 1834 se insertó este anuncio:

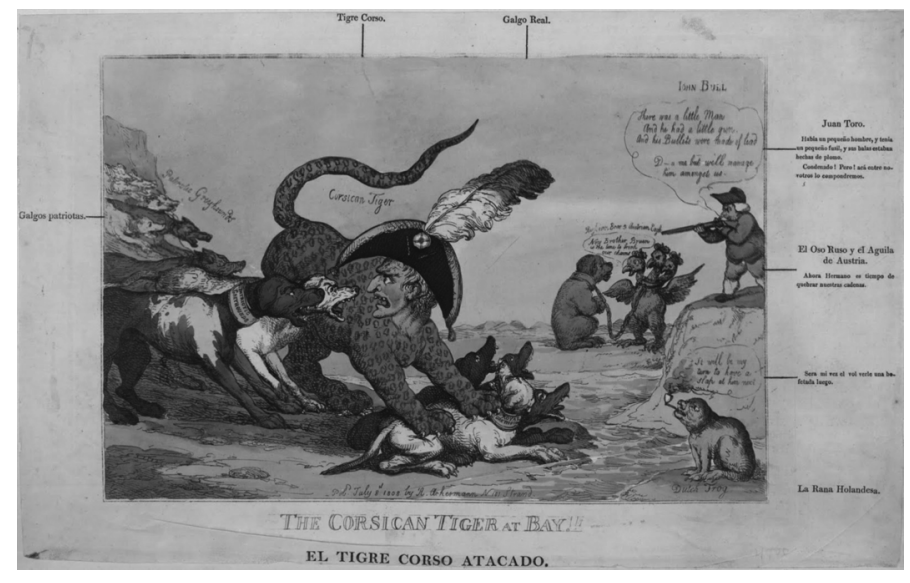

Fig. 3. The Corsican Tiger at Bay!!/El tigre corso atacado, grabada por Thomas Rowlandson y publicada en Londres por Rudolph Ackermann, 8 de julio de 1808. Bodleian Library, Oxford.

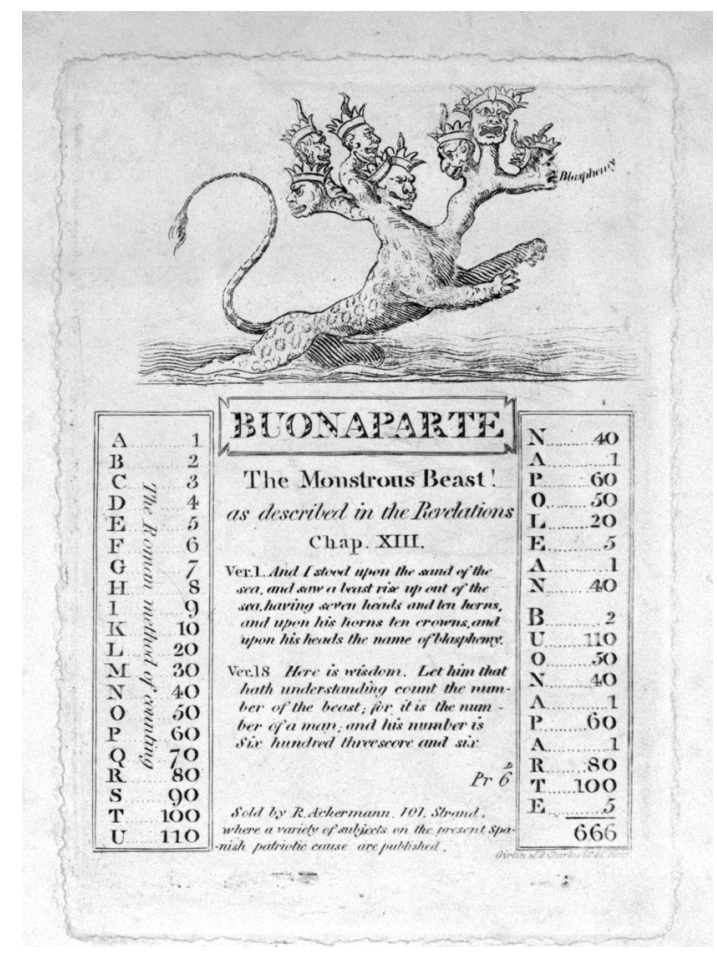

Fig. 4. Buonaparte. The Monstrous beast as describe in the Revelations, Chap. XIII, grabada por James Girtin, Rowlandson y publicada en Londres por Rudolph Ackermann 1808. Musée National du Château de Malmaison, Rueil-Malmaison.

\footnotetext{
${ }^{24}$ Se conserva ejemplar en el British Museum (Londres), 1868,0808.4588 (BM Satires 5534).

25 Biblioteca Nacional de España, mss. 6640.

26 "Dibujo perteneciente a / D. Leandro Fern. ${ }^{z}$ de / Moratín, probablemente / hecho por el mismo. / Estaba entre sus / autografos / A. Barcia", se conserva en la Biblioteca Nacional de España (DIB/18/1/8424).
} 


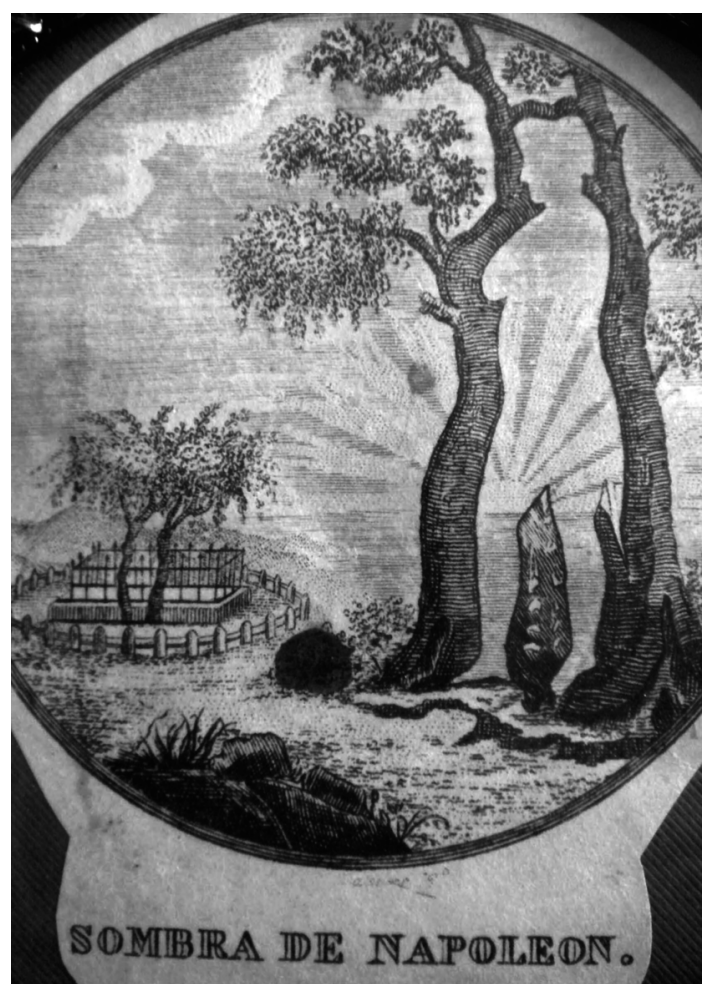

Fig. 5. Sombra de Napoleón, 1834. Colección Margarita Olmo Ruiz, Guadalajara.

La sombra de Napoleón, estampa pequeña que representa el sepulcro de aquel hombre extraordinario, y su sombra de cuerpo entero, de un modo tan ingenioso que no se nota a primera vista, no obstante que forma la parte principal del cuadro. Véndese a $2 \frac{1}{2}$ reales en el almacén de estampas de la calle del Carmen frente a la del Olivo, y en el de la de Carretas frente a la de Majaderitos (fig. 5). ${ }^{27}$

La desmemoria de la que fue objeto la figura de Napoleón entre los españoles devuelve ese suceso a la actualidad, sumergidos como estamos en este debate en relación con la guerra de 1936 que tanto miró y resignificó la de 1808 . Por decreto Fernando VII eliminó los años que duró la contienda, pero consta que ni el olvido ni la amnesia histórica habían hecho mella en 1821, cuando de nuevo héroes y hazañas volvieron al primer plano y se constituyeron en referentes de la lucha contra el servilismo al tirano, en esta ocasión el otrora "deseado". Como afirma Castilla del Pino, "los muer- tos no hacen nada por ellos mismos", son los vivos los que deciden quienes merecen ser recordados y cómo. ${ }^{28}$ En apenas dos décadas el invasor Napoleón se había tornado en un "hombre extraordinario", es decir en un hombre "fuera de orden o regla natural o común", según el sentido que se le daba al adjetivo en el diccionario de la Academia de 1832.

No tenemos información sobre los posibles compradores de La sombra de Napoleón, si bien por la técnica, el tamaño y el precio iba destinado a un público amplio. El mero hecho de que se pusiera a la venta demuestra que el estampero pensaba que el ingenio mostrado en la representación -la estampa se encuentra en la línea de los retratos invisibles-, y el personaje desprovisto de cualquier referente histórico peninsular, eran atractivos. No había transcurrido un año desde la muerte de Fernando VII y los que aspiraban al trono se encontraban en plena contienda, luego es posible que la figura de Napoleón resultara ajena. Entonces la estampa se transforma en un hito en el proceso de desmemoria del dolor y el sufrimiento padecido por los españoles en pro de la reformulación de la contienda en términos de patriotismo y heroísmo, un proceso que estaría oficialmente asentado treinta años más tarde y ha llegado prácticamente formulado en los mismos términos hasta nosotros. ${ }^{29}$

Como decíamos al principio, la amplia y actualizada bibliografía sobre cómo se forjó la imagen de Napoleón ha rastreado de manera consistente las fuentes y los referentes textuales y visuales, especialmente en los últimos años con motivo de su caía definitiva en 1815, pero apenas hemos empezado a conocer lo que pasó después, en el caso español se debe en parte a que la Guerra de la Independencia se ha transformado en una guerra sin final: nadie se acordó de conmemorar su final en 2014 porque, lo que siguió al desenlace, sigue sin gustarnos y no acabamos de asumirlo. El objetivo de rastrear esa parte del archivo visual que había quedado perdido evidencia un pasado proceso de desmemoria y/o de transformación de la memoria que no ha sido suficientemente investigado; ocuparnos de él, además de devolvernos a 1832 puede, quizá, alumbrar reflexiones para el presente.

\footnotetext{
27 Publicada por CUENCA RUIZ, Emilio y OLMO RUIZ, Margarita del. 2013, lám. 26, p. 62.

28 CASTILLA DEL PINO, Carlos. 2006, p. 15.
}

${ }^{29}$ El ejemplo más elocuente es el cambio que introdujo la Academia de San Fernando a la célebre serie que Francisco de Goya tituló Fatales consecuencias de la sangrienta guerra con Buonaparte. Cuando la institución preparó la primera edición en 1863 optó por universalizar la obra del artista bajo el título Los desastres de la guerra. 


\section{Bibliografía citada}

AZCUE, Leticia. El Museo de la Real Academia de Bellas Artes de San Fernando: la escultura y la Academia. Tesis doctoral, Madrid: UCM, 1991. http://webs.ucm. es/BUCM/tesis/19911996/H/0/H0002205.pdfb [consulta 24 de marzo 2018].

AGUILAR PIÑAL, Francisco. Índice de poesías publicadas en los periódicos españoles del siglo XVIII. Madrid: CSIC, 1981.

CASTILLA DEL PINO, Carlos. "La forma moral de la memoria. A manera de prólogo", en GÓMEZ ISA, Felipe (dir.) El derecho a la memoria. San Sebastián: Diputación Foral de Gipuzkoa, 2006, pp. 15-20.

CLAYTON, Tim y O'CONNELL, Sheila. Bonaparte and the British Prints and Propaganda in the Age of Napoleon. Londres: The British Museum, 2015.

CUENCA RUIZ, Emilio y OLMO RUIZ, Margarita del. Iconografía de la Guerra de la Independencia. Guadalajara: Intermedio Ediciones, 2013.

GONZÁLEZ DE LAS HERAS, Natalia. Servir al rey y vivir en la corte: propiedad, formas de residencia y cultura material en el Madrid borbónico. Propiedad y formas urbanas Madrid XVIII. Tesis doctoral, Madrid: UCM, 2014. http://eprints.ucm.es/29493/1/T35963.pdf [consulta 24 marzo 2018].

HARRIS, Katherine D. "The Legacy of Rudolph Ackermann and Nineteenth-Century British Literary Annuals", BRANCH: Britain, Representation and Nine-
teenth-Century History, http://www.branchcollective. org/?ps_articles=katherine-d-harris-the-legacy-of-rudolph-ackermann-and-nineteenth-century-british-literary-annuals [consulta 24 marzo 2018].

LARRIBA, Elisabel. "La contribución de la Gaceta de Madrid al desprestigio de Carlos IV y del Antiguo Régimen por la exaltación de Napoleón (1804-1808)". Cuadernos de Historia Moderna, Anejos, v. VII, 2008, pp. 239-276.

ORCÁRIZ GIL, Pablo. "Los grafitos del claustro de la catedral de Pamplona: dibujos destacados y torres medievales", Trabajos de arqueología Navarra, n. 20, 2007-2008, pp. 285-310.

QUINTANILLA MARTINEZ, Emilio. "'1804. Muera Napoleón el invasor' en el claustro de la catedral de Pamplona", en P. Orcáriz Gil (coord.), La memoria en la piedra: estudios sobre grafitos históricos. Pamplona: Dirección General de Cultura-Institución Príncipe de Viana, 2012, pp. 57-68.

SÁNCHEZ ESPINOSA, Gabriel. "Antonio y Gabriel de Sancha, libreros de la llustración y sus relaciones comerciales con Inglaterra". Bulletin of Spanish Studies, v. 91, n. 9-10, 2014, pp. 217-259.

VEGA, Jesusa. "Bartolomé Sureda y las técnicas gráficas", en Bartolomé Sureda. Arte e industria en la llus tración Tardía. Madrid: Museo Municipal de Madrid, 2000, pp. 171-196.

VEGA, Jesusa. Ciencia, arte e ilusión. Madrid: CSIC/Polifemo, 2011. 
